\title{
SEL DIGEST
}

\section{Abundance cannot represent antibiotic resistance risk}

\author{
Haifeng Qian ${ }^{1, *}$, Zhenyan Zhang ${ }^{1}$, Qi Zhang ${ }^{1}$, Tao Lu ${ }^{1}$, Yong-Guan Zhu ${ }^{2,3}$ \\ 1 College of Environment, Zhejiang University of Technology, Hangzhou 310032, China \\ 2 Key Laboratory of Urban Environment and Health, Institute of Urban Environment, Chinese Academy of Sciences, Xiamen 361021, China \\ 3 University of Chinese Academy of Sciences, Beijing 100049, China
}

(c) Higher Education Press 2022

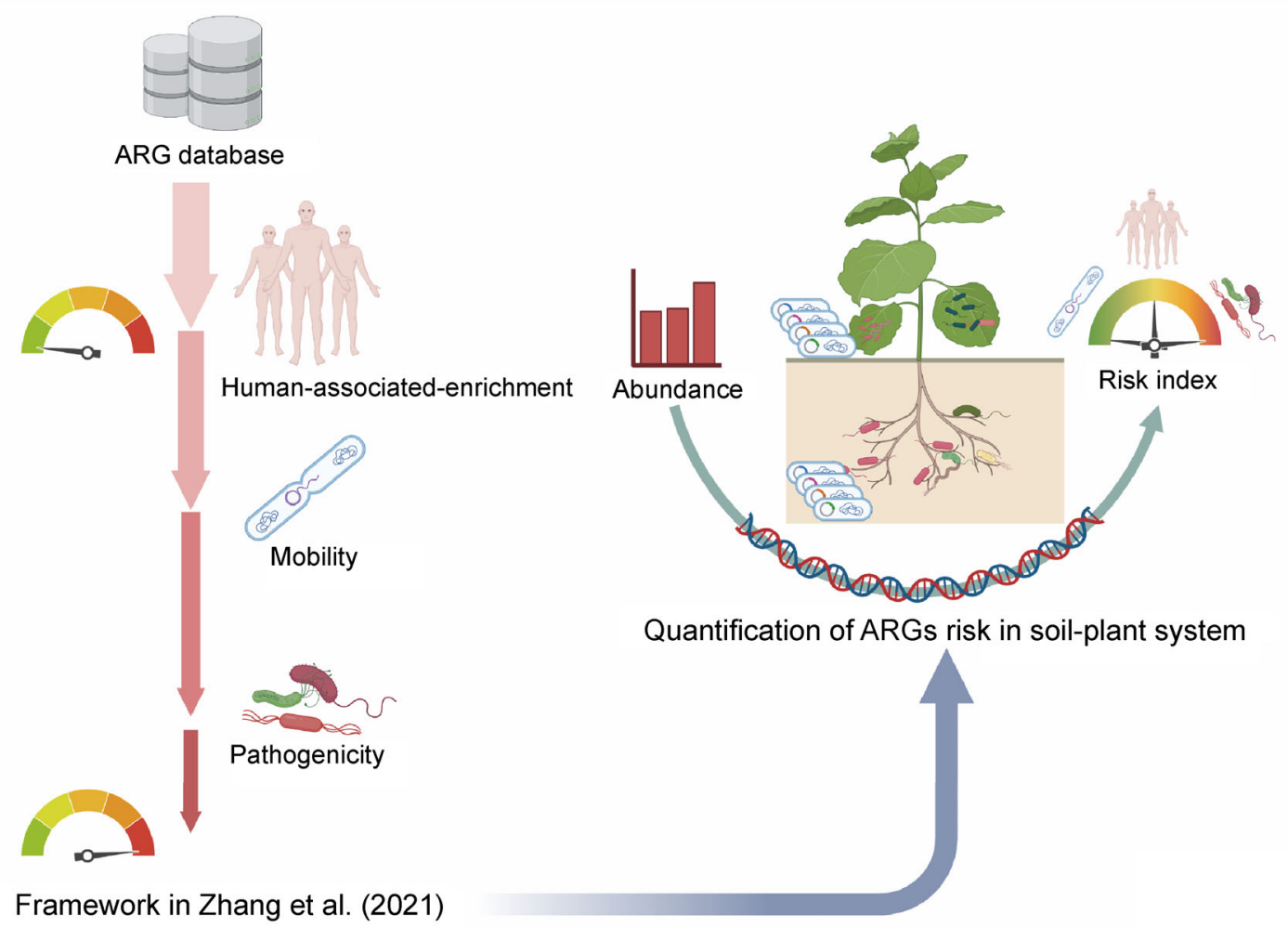

Fig. 1 Quantification of ARGs risk in soil-plant system.

Antibiotic resistance is increasing in the soil environments (Chen et al., 2019a; Zhu et al., 2019) and transferring into human body via plant microbiome, which can be exacerbated by the food chain, direct contact pathway, and globalization process (Chen et al., 2019b). However, antibiotic resistance is not the newborn from anthropogenic activities, as it has been detected in the permafrost (D'Costa et al., 2011) and human paleofeces (Wibowo et al., 2021). More interestingly, some of the ancient antibiotic resistance genes did not exhibit the resistance to antibiotics (Martínez et al., 2015), but showed a range of environmental functions, such as liberating phosphorus from phosphate (McRose and Newman, 2021), or encoding efflux pumps (Piddock, 2006). All these evidences indicated that we cannot just assess the health risk of soil

Accepted October 27, 2021

* Corresponding author

E-mail address: hfqian@zjut.edu.cn (H. Qian) 
antibiotic resistome based on their abundance. In Nature Communications, Zhang et al. (2021) developed a metagenome-based framework to comprehensively assess the health risk of 2579 antibiotic resistance genes (ARGs) into four ranks by considering the human-associated-enrichment, gene mobility, and host pathogenicity. Only $3 \%$ of total assessed ARGs were considered as the top risky ones, which were enriched in the human-associated ecosystems, carried by mobile genetic elements and hosted by pathogens. This framework provided a viable approach to evaluate the health risks of current and future ARGs and made a step forward in comprehensive investigation of antibiotic resistome profile in diverse ecosystems. Based on this framework, future study in soil can focus on how to quantify the health risk, rather than ranking into several groups of each ARGs, and more importantly, trying to replace the abundance with "risk index" to evaluate the health risk of global soil antibiotic resistome as well as their interaction with plant microbiome and human body.

\section{References}

Chen, Q.L., An, X.L., Zheng, B.X., Gillings, M., Peñuelas, J., Cui, L., Su, J.Q., Zhu, Y.G., 2019a. Loss of soil microbial diversity exacerbates spread of antibiotic resistance. Soil Ecology Letters 1, 3-13.

Chen, Q.L., Cui, H.L., Su, J.Q., Penuelas, J., Zhu, Y.G., $2019 \mathrm{~b}$. Antibiotic resistomes in plant microbiomes. Trends in Plant Science
24, 530-541.

D'Costa, V.M., King, C.E., Kalan, L., Morar, M., Sung, W.W.L., Schwarz, C., Froese, D., Zazula, G., Calmels, F., Debruyne, R., Golding, G.B., Poinar, H.N., Wright, G.D., 2011. Antibiotic resistance is ancient. Nature 477, 457-461.

Martínez, J.L., Coque, T.M., Baquero, F., 2015. What is a resistance gene? Ranking risk in resistomes. Nature Reviews Microbiology 13 , 116-123.

McRose, D.L., Newman, D.K., 2021. Redox-active antibiotics enhance phosphorus bioavailability. Science 371, 1033-1037.

Piddock, L.J.V., 2006. Multidrug-resistance efflux pumps? not just for resistance. Nature Reviews Microbiology 4, 629-636.

Wibowo, M.C., Yang, Z., Borry, M., Hübner, A., Huang, K.D., Tierney, B. T., Zimmerman, S., Barajas-Olmos, F., Contreras-Cubas, C., García-Ortiz, H., Martínez-Hernández, A., Luber, J.M., Kirstahler, P., Blohm, T., Smiley, F.E., Arnold, R., Ballal, S.A., Pamp, S.J., Russ, J., Maixner, F., Rota-Stabelli, O., Segata, N., Reinhard, K., Orozco, L., Warinner, C., Snow, M., LeBlanc, S., Kostic, A.D., 2021. Reconstruction of ancient microbial genomes from the human gut. Nature 594, 234-239.

Zhang, A.N., Gaston, J.M., Dai, C.L., Zhao, S., Poyet, M., Groussin, M., Yin, X., Li, L.G., van Loosdrecht, M.C.M., Topp, E., Gillings, M.R., Hanage, W.P., Tiedje, J.M., Moniz, K., Alm, E.J., Zhang, T., 2021. An omics-based framework for assessing the health risk of antimicrobial resistance genes. Nature Communications 12, 4765. Zhu, D., Wang, H.T., Zheng, F., Yang, X.R., Christie, P., Zhu, Y.G., 2019. Collembolans accelerate the dispersal of antibiotic resistance genes in the soil ecosystem. Soil Ecology Letters 1, 14-21. 